\title{
A Escola Francesa e as definições de poder Georges Burdeau e Michel Foucault
}

\author{
Luiz Alberto G. S. Rocha \\ luizalbertorocha@unama.br \\ Brasil \\ Doutor em Direito do Estado pela USP \\ Professor Titular da \\ Universidade da Amazônia - Unama \\ Recebimento do artigo: 11/12/2008 \\ Aprovado em: 10/12/2009
}

\section{Resumo}

O trabalho apresenta duas posições da condições de entender a luta contempoEscola Francesa acerca da natureza e exercício do poder estatal. Primeiro, a visão modernista de Georges Burdeau e, posteriormente, a contraposição pós-moderna de Michel Foucault. Ao confrontar as duas estéticas de trabalho, ter-se-á maiores rânea pela realização cotidiana de direitos constitucionais fundamentais.

\section{Palavras-chave}

Georges Burdeau. Michel Foucault. Poder. Modernismo. Pós-Modernismo. 


\title{
The French School and the definitions of power
} Georges Burdeau and Michel Foucault

\author{
Luiz Alberto G. S. Rocha
}

\section{Abstract}

The essay presents two positions of French School about the nature and the exercise of the State Power. First the modernist vision of Georges Burdeau and, afterwards, the postmodern counteraction of Michel Foucault. By confronting the two aesthetics of work we'l have great conditions to understand the contemporary struggle for the everyday realization of fundamental constitutional rights.

\section{Key words}

Georges Burdeau. Michel Foucault. Power. Modernism. Postmodernism. 


\section{Sumário}

1 Introdução.

2 Importância do poder e os Direitos humanos.

3 Georges Burdeau e a placidez moderna.

4 Desconstrução do Pós-modernismo.

5 A leitura de Nietzsche em Michel Foucault.

6 Conclusão.

Referências

\section{Introdução}

A primeira preocupação que possa se imaginar quando a vida em sociedade se estabelece é a percepção de que há necessidade de se criar um vínculo de coerência entre os indivíduos, que possa lhes conduzir à realização do objetivo principal de ser da vida em sociedade.

Isso é claramente perceptível porque a ordem de relação entre as pessoas requer um fio condutor para que a multiplicidade de interesses e ações não acabe gerando muito mais uma desagregação no viver coletivo do que efetivamente uma multiplicação do bem-estar individual.

É talvez nesse sentido principal que a questão do poder tem surgido nos estudos do Estado, pois sua gênese tem interferência direta na realização, mesmo do sentido de sociedade e do próprio Estado. É pelo poder que as relações sociais se determinam e é pelo poder que o Estado exerce suas atribuições sociais, mas também é pelo poder que surge a separação entre governantes e governados, entre oprimidos e opressores e é pela existência de um poder descontrolado que grupos humanos inteiros reclamam direitos fundamentais. Eis assim que o poder tem um semblante controverso, tanto de benfeitor pela necessidade de regulação da vida em sociedade, quanto de malfeitor pelas desigualdades sociais que pode fomentar. De qualquer forma, o assunto do poder é um tema preponderante para quem queira entender o Estado. 
Desta forma é possível perceber que o Estado Moderno, ao se configurar como resposta social e política ao caos vivido na Idade Média, trazendo a iluminação da razão como elemento condutor do desenvolvimento humano, não chegou a lograr sobrepujar a ótica de dominação que impunha pesado fardo sobre os indivíduos comuns.

$\mathrm{Na}$ realidade, a lógica estabelecida pelo Estado Moderno produziu um ser enclausurado que se pode depreender pela mudança pré-ordenada do conjunto de valores naturalísticos, em favor da produção racional do agir social em que a própria ideia do ser sucumbiu diante da necessidade do ter.

A busca do presente trabalho não é necessariamente apresentar os modelos de enclausuramento do homem moderno, nem mesmo desconstruir passo-a-passo a racionalidade moderna para dar a perceber como o indivíduo moderno se tornou refém desta lógica, muitas vezes imperceptível no seu modus operandi, mas com resultados coletivos bastante tangíveis como a insegurança pública e as crises econômica e ambiental.

A pretensão é demonstrar por meio de dois ícones da escola francesa como a leitura do aspecto do poder, tão vital para a realização dos direitos fundamentais, modificou-se fortemente com o pós-modernismo. E que, em grande sentido, eles refletiram um conceito de Estado, de Poder próprio das correntes de pensamento que defenderam o que pode nos auxiliar a entender melhor as disputas de poder contemporâneas. Pois, só as entendendo com maior coerência é que conseguiremos partir para a aventura de realização cotidiana de direitos constitucionais fundamentais, demandados fortemente pela sociedade.

\section{Importância do Poder e os Direitos Humanos}

A essência da vida em comunidade requer a formação de uma estabilidade das relações entre os indivíduos, que mantenha as ações individuais em um nível de tolerância aceitável pelo conjunto social. Isso se pensarmos que a vida em comunidade dependa da racionalização de um objetivo comum a ser alcançado, que essencialmente nos faça viver conjuntamente, e de meios, legais, para concretizá-los. Logo iremos perceber que uma maneira essencial de realizar tais desígnios é exatamente implementar políticas de ação coletiva, comum.

Acontece que é ilusão política imaginar que políticas comuns sejam efetivamente comuns. Digo, o mais habitual é que os indivíduos identifiquem caminhos diversos para a concretização de objetivos similares; logo, concluiremos que os meios não 
são uniformes. E aí surge um outro problema: como fazer com que interesses frequentemente divergentes possam se converter para uma ação comum?

Um dos papéis do Estado é fazer com que se ache um equilíbrio entre interesses individuais díspares que possam se concretizar em uma política comum, ou melhor, em uma política de convergência que possa significar o atendimento da maior parte dos interesses dos indivíduos - pelo menos se usarmos o padrão democrático, o princípio do interesse da maioria deve prevalecer. Já que nem todos os interesses são albergados pela política comum governamental, o modo de fazê-la cumprir é exatamente adotar a imperatividade da ação estatal com uso do Poder Social.

Nesse sentido, simploriamente traçada a natureza do Poder Social, vemos que ele não é senão uma ferramenta que instrumentaliza a concretização de objetivos sociais. Ele garante, sob a égide do Poder institucionalizado no Estado, que os objetivos soberanos de realização do bem-comum por meio de políticas governamentais sejam efetivamente cumpridos.

E talvez o leitor já tenha imaginado que esbarramos com uma outra questão sobre o Poder Social, e talvez a principal questão: se o modo de fazer cumprir o traçado como política comum é muitas vezes utilizar a imperatividade do Estado, então como fazer para que tal Poder não fuja ao controle tanto do agente público que dele se utiliza, quanto das rédeas do próprio conjunto social representado pelo Estado?

Se continuarmos imaginando o Poder como instrumento de realização de planejamentos sociais, também poderemos afirmar que a princípio ele não representa senão uma ferramenta estéril que pode tanto servir realmente ao conjunto social quanto pode apoiar interesses duvidosos de grupos sociais que se utilizam dos órgãos de poder estatal em proveito próprio.

Acho que se pudéssemos resumir os mais variados estudos sobre a temática do Estado e o Poder, encontraríamos um ponto em comum exatamente na incessante busca por mecanismos de controle do Poder Social, de forma a abstê-lo de assumir facetas segregadoras das classes sociais.

O mais óbvio que se pode fazer para chegar à análise aprorística do Poder é tentar eliminar o risco de seu mau uso. Expliquemos. Se há, como sempre houve, chances de o Poder ser mal utilizado em prejuízo da sociedade, então um modo abrupto, mas eventualmente eficaz, de eliminar tal problema seria cortá-lo pela raiz. Isto é, qualquer traço de Poder social deve ser eliminado do meio estatal evitando que o homem tenha a tentação de abusar de seu uso em prejuízo de seus semelhantes.

Quem fala de poder político, fala de dominação. Quando existe dominação, uma grande parcela da sociedade é dominada e os que são dominados geralmente detes- 
tam os que dominam, enquanto estes não têm outra escolha, a não ser subjugar e oprimir aqueles que dominam. Esta é a eterna história do saber, desde que o poder surgiu no mundo. Isto é, o que também explica como e porque os democratas mais radicais, os rebeldes mais violentos se tornam os conservadores mais cautelosos assim que obtêm o poder. Tais retratações são geralmente consideradas atos de traição, mas isto é um erro. A causa principal é apenas a mudança de posição e, portanto, de perspectiva. ${ }^{1}$

A crença na necessidade do Estado é a descrença na natureza humana, porque uma sociedade só pode ser idealmente construída quando todos não precisarem de comandos a obedecer, mas realizarem tudo voluntariamente, percebendo as vantagens da solidariedade no conjunto social, organizando-se em governo auto gestionário. Qualquer coação de poder na determinação do que fazer é necessariamente uma intervenção na condição natural do homem de realizar-se plenamente em sociedade.

Ainda que tais princípios éticos do anarquismo tenham cooptado uma geração de revolucionários, ele não conseguiu superar a síntese do pensamento liberal quanto à necessidade do Estado, e consequentemente do poder que ele institucionaliza, com a afirmação que

a sociedade é produzida por nossas necessidades e o governo por nos-
sa perversidade; a primeira promove a nossa felicidade positivamente
mantendo juntos os nossos afetos, o segundo negativamente manten-
do juntos os nossos vícios. Uma encoraja as relações, o outro cria as
distinções. A primeira protege, o segundo pune. A sociedade é sob
qualquer condição uma dádiva; o governo, inclusive na sua melhor
forma, nada mais é que um mal necessário, e na sua pior forma é
insuportável. ${ }^{2}$

Essa forma sintética de superar o questionamento sobre a necessidade do Estado determinou a construção moderna da sociedade por intermédio de um pragmatismo racional que revelou, também sob o enfoque capitalista, a construção de uma objetividade economicamente produtiva no modo de encarar o mundo.

O eixo de solução aos problemas pode ser sintetizado, na organização do Estado, segundo critérios racional e cartesiano de formação de uma estrutura modelar que, auxiliada pelo positivismo novecentista, produz uma resposta pretensamente satisfatória aos desafios da sociedade. Aliás, a crítica pós-moderna que se fará mais adiante com Michel Foucault é exatamente essa onipotência de uma pretensa objetividade e neutralidade epistêmica que não levanta o véu das vicissitudes sociais.

\footnotetext{
BAKUNIN, Mikhail. L’Illusion du Suffrage Universel. In: Ouvres, v. II. Paris: s/ed, 1907, p. 153.

2 PAINE, Thomas. Senso comune. Roma: Riuniti, 1978, p. 69.
} 


\section{Georges Burdeau e a placidez moderna}

Georges Burdeau (1905-1988), professor da Faculdade de Direito de Dijon e Paris, destacou-se entre seus contemporâneos, ao lado de Léon Duguit (18591928), por construir uma teoria universalizante de explicação do Estado e seus fenômenos.

É sintomático que, mesmo criando um debate acadêmico com Duguit, Burdeau não se diferencia muito dele, pois atribui ao Estado todas as funções catalisadoras da realização dos direitos fundamentais, agindo como uma mão invisível reguladora de uma sociedade de solidariedade. Ou seja, é a racionalização da idéia de direito que fornecerá a solução social de harmonização dos interesses coletivos.

Para Burdeau, a sociedade organiza-se por uma disciplina coletiva que objetiva a realização do bem comum que só pode ser conquistado por meio de regras jurídicas coercitivamente impostas por um poder. Assim, "o poder é uma força a serviço de uma ideia". ${ }^{3}$

O poder não existe somente no Estado, mas é o locus relevante de sua concretização, pois ele relaciona a capacidade de realização de um comportamento desejado com conteúdo social. É a finalidade social o elemento que revela sentido próprio ao poder do Estado, que lhe estabelece uma tez política ganhando uma existência socialmente organizada ao instrumentalizar a realização do bem comum.

Esse exercício do poder social pelo Estado legitima-se na Ideia de Direito, que é a reunião coletiva de pretensões individuais que, ordenadas no meio social, ganham relevo coletivo. É a própria finalidade de existência do ser coletivo. Ou seja, a constatação da necessidade de ordem em torno da realização do projeto coletivo de harmonização das partes produz essa energia social que coloque em marcha o desejo coletivo.

Assim, o meio social é capaz de pensar nos fins sociais, permitindo a existência de um ser abstrato racionalizado que, por meio do poder social, supera a inércia caótica de base primitiva, civilizando as ações individuais em benefício da realização coletiva da Ideia de Direito: o Estado.

Os mecanismos próprios para a tal busca coletiva são as regras de direito valoradas em sua correspondência direta com a realização da Ideia de Direito. E "nesse sentido podemos dizer que todo o direito é o instrumento de uma política". ${ }^{4}$

Sendo assim, o papel do Poder é justamente intermediar a Ideia de Direito, ele-

3 BURDEAU, Georges. Méthode de la science politique. Paris: Dalloz, 1959, p. 188.

4 BURDEAU, Georges. Op. cit., p. 197. 
mento fundador da regra, e o direito positivo, fenômeno concretizante - o que, com o advento do constitucionalismo, será a função do poder constituinte. O Poder é exatamente o instrumento adequado para concretizar o conjunto das ideias e princípios existentes na sociedade. Ele não tem iniciativa, nem autonomia, não é autopropulsor. Seu papel é essencialmente técnico, pois "positiva" a consciência dos homens e a natureza das coisas. ${ }^{5}$

Percebe-se, portanto, que toda a teoria de Burdeau está fundada na Ideia de Direito que pode ser explicada por uma abordagem sociológica, como "um estado de consciência social formada por fatores materiais e psicológicos que se expressam na adesão ao objetivo social no qual o conteúdo não é outro senão o Bem Comum”‘ Justifica, então, o exercício do poder social pela realização de sua missão de transformação do grupo humano em um grupamento sociologicamente coeso.

O que se reflete na abordagem jurídica da Ideia de Direito, ou seja, na realização de consensus social, dá-se graças de um conjunto de regras de direito que disciplinam a vida em sociedade, orientando comportamentos individuais com expectativa de realização futura do bem comum. Seguem-se as regras de direito como mecanismo essencial de realização da ordem e, por via de consequência, da concretização da Ideia de Direito.

Esse poder organizador da sociedade na busca do bem comum é a passagem da ordem abstrata de desejos coletivos para uma ordem jurídica concreta, estabelecedora de um sistema de normas que postula ser a representação jurídica da abstração tida na Ideia de Direito.

Eis, em conclusão, a coerência absoluta da teoria de Burdeau. Sociedade e direito, Ideia e regra de Direito, Ideia de Direito e poder são inseparáveis. O isolamento de um desses fatores só serve para compreender didaticamente a complexidade do sistema, pois na verdade eles são todos, ao mesmo tempo, uma unidade globalizante. ${ }^{7}$

Nesse contexto, é fácil perceber a correlação lógica da submissão do grupo social à estrutura institucional do Estado pela manutenção da ordem na realização do bem comum. Mesmo porque a Ideia de Direito prevê certo aceitamento da ordem estatal como ordenadora do desejo coletivo, da tomada de decisões em nome da coletividade. Nela o governante assume posicionamento plácido na simples instrumentalização das vontades coletivas. Há, aliás, um quê de similaridade com o

\footnotetext{
5 ROCHA, Luiz Alberto G. S. Estado, democracia e globalização. Rio de Janeiro: Forense, 2008, p. 68.

6 Idem, ibidem, p. 69.

7 Idem, ibidem, p. 70.
} 
governante rousseauniano que não realiza nenhum ato contrário ao desejo coletivo, simplesmente porque, agindo assim, estaria atentando contra a própria sociedade na qual ele está inserido. É, pois, o elemento mais característico, e criticado, da racionalidade moderna: a coerência completa dos sujeitos. ${ }^{8}$

\section{Desconstrução do Pós-modernismo}

A primeira impressão a cair por terra na virada do século é a ideia de placidez, que nos manteve durante boa parte do pós-guerra altivamente paralisados, na esperança irrealizada de que os mecanismos liberais do Estado Moderno nos pudesse cumprir as promessas constitucionais impregnadas em seus textos.

As reações político-sociais vivenciadas desde maio de 68 nos mostraram e nos mostram hoje, na imposição real de um mundo globalizado, que os mecanismos de explicação e formação moderna não foram suficientes para contemplar grande parte da sociedade com os benefícios sociais do Estado Providência.

A escola francesa clássica, representada neste trabalho pelas ideias de Georges Burdeau, refletiu essas promessas de um Constitucionalismo liberal que, ao colocar a razão como instrumento de realização do desejo coletivo, mobilizaram uma interpretação estática do contexto social distanciado das soluções de governo, pretensamente em benefício dessa própria sociedade. "A reivindicação por objetivismo e verdades universais do iluminismo liberal não são mais que máscaras de poder político que substituíram com sucesso o poder anterior [dos nobres]”. ${ }^{9}$

É interessante perceber que a dissociação governamental do aspecto valorativo como reflexo da noção de realização da razão por meio, por exemplo, de uma leitura retilínea do princípio da legalidade e do Estado de Direito expôs uma cegueira do pragmatismo produtivo em que o homem se fecha num individualismo isolacionista, por meio do qual a satisfação de sua vida é a aventura do consumo.

A relação humana com o dinheiro e com a conquista, com a natureza e com o caráter empreendedor-destruidor, revelando a anatomia da destrutividade humana, relega também, nas relações de interação social, o outro não produtivo ao esque-

\footnotetext{
"O objetivo era desmontar os sistemas e totalidades dos filósofos modernistas e mostrar como elas eram construídas, não desde elementos naturalmente coerentes, mas a partir dos elementos heterogeneamente dissonantes ou a partir dos elementos arbitrariamente selecionados para excluir qualquer coisa que não tenha coerência”. TEBBIT, Mark. Philosophy of law: an introduction. Londres: Routledge, 2005, p. 74.

9 TEBBIT, Mark. Op. cit., p. 76.
} 
cimento, o que reforça o caráter fálico, concorrencial, darwinista da corrida pela sobrevivência e pelo descuido com um traço dessa cultura. ${ }^{10}$

Tendo esse contexto de trabalho, o pós-modernismo com o Martelo de Nietzsche influenciou releituras desconstrutivistas que jogam por terra todos os arquétipos de pensamentos e dogmas que impedem ou dificultam a realização de uma aprendizagem nova das realidades sociais que nos circundam. Nesse entender é que passamos à apresentação da influência pós-moderna em Michel Foucault, e com ele, a possibilidade de uma completa nova abordagem do aspecto do poder estatal, ponto fundamental para uma leitura política dos direitos humanos fundamentais.

\section{A leitura de Nietzsche em Michel Foucault}

A proposta de Nietzsche sobre a revolução metodológica de análise da História Moderna possibilita uma participação do homem no fazer a história que contribui como ancoragem do pensamento foucaultiano de análise da estrutura do Estado, pelo foco das relações de poder.

Talvez seja mais preciso dizer que, pela própria abordagem foucaultiana sobre o Direito, não podemos construir, em comparação a Burdeau, uma teoria de Direito foucaultiana em que se pudesse revelar a comparação do pensador francês com as discussões americanas do Critical Legal Studies. Mas são extremamente oportunas as análises do elemento de poder dentro do Estado para entender o funcionamento da proposta pós-moderna da sociedade contemporânea. Ou melhor, a tentativa de superação do reducionismo valorativo do modernismo e a falta de usufruto dos bens de consumo jurídico, previstos nas declarações de direitos humanos fundamentais.

A perspectiva de Michel Foucault (1926-1984), professor de História dos Sistemas de Pensamento do Collège de France, é revolucionária à maneira como o Direito trata o elemento de poder social. É revolucionária porque parte de um discurso desconstrutivo dos elementos e teorias que o Direito normalmente usa para explicar tal concepção, mas, principalmente, porque chega a conclusões que eliminam do Estado a exclusividade das análises do poder, colocando-o em outros espaços e níveis sociais que não são normalmente tratados pelas disciplinas jurídicas.

A concepção revolucionária a que me refiro descreve um quadro de relações de poder onipresentes no corpo social, desenvolvidas por Michel Foucault, no final do

$\overline{10}$ BITTAR, Eduardo C. B. Razão e afeto, justiça e direitos humanos: dois paralelos cruzados para a mudança paradigmática. Reflexões frankfurtianas e a revolução pelo afeto. Revista do Mestrado em Direito. Direitos Humanos Fundamentais. Edifieo, a. 8, n. 1, 2008, p. 101. 
século passado, que podem ser consideradas um neonietzcheísmo devido à abordagem de fundo que Foucault faz do filósofo alemão.

Foucault desenvolve um conjunto de pensamentos presente originalmente em Nietzsche, principalmente em a Genealogia da Moral e Gaia Ciência, que percebe a multiplicidade de relações de poder, estabelecida nos amplos domínios discursivos da sociedade, os quais interferem em diversas direções. A perspectiva de Foucault inicia com uma análise de método que se compõe de uma arqueologia do indivíduo, fato que o distancia da sua origem nietzscheana de indivíduo livre, desviado de seus instintos primários para derivativos antinaturais. Nietzsche apresenta uma concepção irracionalista de que a vida é instinto, e que a razão deriva da vida, mas também, e com maior interesse para Foucault, que a razão é um poder eficaz, muitas vezes responsável por processos incompetentes de autoformação humana.

Apontando genericamente, no entanto, como a principal contribuição que Foucault obteve de Nietzsche, pode-se identificar a metodologia de desconstrução dos mitos sociais (Martelo de Nietzsche), que escondem a limpidez acre da autenticidade humana, possibilitando-nos ir mais além quanto à compreensão jurídica das relações de dominação.

Da psicologia da cultura de Nietzsche deriva uma crítica demolidora dos valores. Mas não há só demolição no pensamento nietzscheano. A demolição é aqui um desmascaramento impiedoso das mistificações, dos desvirtuamentos a que estão expostos os princípios morais. Ao revelar os mecanismos de defesa e o ressentimento, que podem distorcer o sentido dos mais altos valores, conservando-lhes a aparência de autenticidade, Nietzsche adotou, de certo modo, um processo análogo ao desmascaramento ideológico praticado pelo marxismo e a desmistificação terapêutica da psicanálise. ${ }^{11}$

Com esse pano de fundo, Michel Foucault introduz uma metodologia nova de análise genealógica do poder, ou seja, de percepção do nível de existência e transformações que sofrem as relações de poder, incluindo-as como um dispositivo político de dominação pelo discurso.

Não que haja propriamente uma teoria geral do poder em Foucault, mas ele o percebe como uma prática social historicamente constituída (epistéme), que precisa ser entendida em sua dinâmica de desenvolvimento na realidade crua das relações humanas. Pois, a genealogia de poder de Foucault vai além do costumeiramente trabalhado em Direito, que é o Estado como produtor, institucionalizador e mantenedor do poder. Há formas de exercício do poder diferentes do Estado, a ele articuladas de maneiras variadas e que são indispensáveis, inclusive para sua sustentação

$\overline{11}$ NUNES, Benedito. Filosofia contemporânea. Belém: Edufpa, 2004, p. 77. 
e atuação eficaz.

Ela [a genealogia de poder] visa a distinguir as grandes transformações do sistema estatal, as mudanças de regime político em nível dos mecanismos gerais e dos efeitos de conjunto, além de considerar a mecânica de poder que se expande por toda a sociedade, assumindo as formas mais regionais e concretas, investindo em instituições, tomando corpo em técnicas de dominação. Esse poder que intervém materialmente, atingindo a realidade mais concreta dos indivíduos - o seu corpo - e que se situa em nível do próprio corpo social, e não acima dele, penetrando na vida cotidiana e, por isso, podendo ser caracterizado como micro-poder ou subpoder. ${ }^{12}$

Foucault chama Microfísica do Poder a esse deslocamento do espaço de análise (até então exclusivamente estatal) e do nível em que ela se efetua (até então focado em exteriorizações normalizadas). Ele chama atenção para a gama de poderes periféricos que não foram confiscados e absorvidos pelo Estado, mas que se espalham em diversos pontos da rede social num complexo sistema de micropoderes que normalmente não são levados em conta. Até porque em Direito muitas vezes se crê que modificações macrocósmicas realizadas no Estado conduzem, necessariamente, a mudanças no nível molecular de poderes sociais. Que tais mudanças aconteçam pode-se até especular, mas nem se pode tê-las como postulado apriorístico, e por isso não criticável, nem se pode imaginar que só de grandes mudanças pode-se ingerir nas relações de micropoder.

As consequências políticas das ideias de Foucault são principalmente que essas relações de poder não analisadas existem com independência ao Estado, e podem mesmo ter uma influência sobre as ações governamentais. Mas, fundamentalmente, a centralização da discussão, no elemento estatal, faz desviar a atenção de tais outras relações de dominação exercidas em níveis mais restritos do corpo social:

são os mecanismos de exclusão, os aparelhos de vigilância, a medicalização da sexualidade, da loucura, da delinquência, é toda esta micromecânica do poder que representou um interesse para a burguesia a partir de determinado momento. ${ }^{13}$

A voz de Foucault é uma das que desconfia desse Direito que emite com exclusividade a fala do poder. Ele coloca em xeque os fundamentos racionais da autoridade política, fazendo um questionamento radical do positivismo jurídico.

É certo que Foucault fez incursões em vários fragmentos da sociedade para localizar e descrever os discursos de poder, tanto na História da Loucura, como na

12 MACHADO, Roberto. Introdução. Por uma genealogia do poder, p. XII. In: FOCAULT, Michel. Microfísica do poder. 8. ed. Rio de Janeiro: Graal, 1979.

13 FOUCAULT, Michel. Soberania e disciplina. In: Microfísica do poder. 8. ed. Rio de Janeiro: Graal, 1979, p. 185. 
História da Sexualidade, n'O Nascimento da Clínica, em Vigiar e Punir. Todavia, em todos os casos, interessava-lhe desgastar as aparências que a ritualização do poder fazia construir, e demonstrar o verdadeiro âmbito de suas relações:

A burguesia não se interessa pelos loucos, mas pelo poder; não se interessa pela sexualidade infantil, mas pelo sistema de poder que a controla; a burguesia não se importa absolutamente com os delinquentes nem com sua punição ou reinserção social, que não têm muita importância do ponto de vista econômico, mas se interessa pelo conjunto de mecanismos que controlam, seguem, punem e reformam o delinquente. ${ }^{14}$

O resultado desse processo metodológico é analisar o poder como uma estrutura capilar, que se ramifica em diversificados pontos das relações sociais, por meio de formas e instituições mais regionais e locais, em que muitas vezes as regras do direito não chegam a organizar e delimitar a ação dos indivíduos. É a epistéme do racionalismo moderno que se centraliza na ideia do Estado como órgão central e único de poder, cuja negativa em analisar suas outras relações, encobre os jogos de poder que se espalham dentro da sociedade e que compõem relações de dominação não desprezíveis. Relações que raramente são percebidas, mas que atuam na determinação e constituição do sujeito.

O constrangedor nesse aspecto é constatar que o Direito se auto-proclamou, na alvorada do racionalismo moderno, o redentor do caos social da Idade Média. Entretanto não dispõe de instrumentos de identificação desses micro-poderes e, menos ainda, de des-sujeição dos poderes disciplinares.

Foucault procura tornar evidente a questão da arbitrariedade dos modos de ser sociais; especialmente em As palavras e as coisas o que está subnominem não é efetivamente o que é; nada é por essência, mas por atribuição, e isto se faz e se constrói historicamente, dentro de espaços sociais constituídos a partir de saberes e discursos predominantes..$^{15}$

À primeira vista, um aspecto da realidade dada em verdade não o é, mas tem sido assim em decorrência da construção humana fundada na história, que concebe aquilo que parece ser a natureza, a verdade, a ratio assendi do universo. Foucault demonstra que o discurso da verdade não traduz a essência última das coisas; há entre estas as palavras, a mediação de um modo de apropriação da realidade que lhe confere certo sentido, cuja noção é a relação entre os saberes e o poder, entre o poder e as relações de poder. E é a desconstrução de tais relações de poder, de "verdade", que se constitui a verdadeira tarefa política.

Volta-se, portanto, ao ponto de que o poder não é um objeto natural, do qual se

$\overline{14}$ FOUCAULT, Michel. Op. cit., p. 186.

15 BITTAR, Eduardo C. B. Curso de filosofia política. 2. ed. São Paulo: Atlas, 2005, p. 293. 
detenha alguma posse efetiva, mas se constitui em práticas sociais, práticas de saber, que determinam a constituição dos objetos naquilo que se quer que eles sejam e dos indivíduos em seres amoldados e socializados, a partir das estratégias de poder.

Sob esse enfoque específico, muitas vezes o conceito de lei aparece como mero instrumento de socialização, normalização dos comportamentos a modelos semelhantes, a partir de uma média de comportamento que deve se assemelhar, disciplinando instituições sociais, educacionais, políticas e jurídicas. Nesse sentido, o Direito é também uma das estruturas do discurso de normalização e de institucionalização do direito do mais forte. Em Vigiar e punir, Foucault demonstra claramente a dimensão de objetivos que as prisões contemporâneas têm, mostrando as leis como um disfarce à manifestação pura e simples da violência dos mais fortes.

O poder disciplinar levado a cabo pelo Direito é explicado em três aspectos: (1) da vigilancia hierárquica, que ocorre em instituições como escola e hospital e que torna um poder múltiplo, automático e anônimo; (2) da sanção normalizadora, que se localiza abaixo de uma dimensão estritamente jurídica e busca desvios para restabelecer uma ordem, ordem esta que é construída artificialmente. Daí surgir o castigo disciplinar que, por meio da punição, implementa uma série de sanções positivas, de forma a corrigir e disciplinar o indivíduo à média da sociedade

com isso, a sanção hierárquica desempenha um papel importante na função disciplinar que é o de estabelecer hierarquias, fixar critérios de classificação e formatar meritoriamente os comportamentos, recompensando de um lado e rebaixando ou degradando de outro.

E, pelo (3) do exame, que é o sistema de registro e acumulação de documentos, responsável por individualizar e visualizar os indivíduos para que sejam mecanismos de exercício do poder,

o indivíduo aparece aqui como um objeto descritível e analisável, passível de ser reduzido a uma caracterização de fenômenos coletivos, viabilizando desta forma todo um sistema de comparações e de descrição do comportamento das "populações". ${ }^{16}$

A amplitude de tais elementos converge para uma posição de mobilização contra o exercício do poder, capaz de normalizar e absorver o homem nas suas teias, fazendo-o imóvel a seus elementos de dominação, porque ele fica adstrito à epistéme de sua própria época. Lutar, dentro do caráter relacional do poder em sociedade, é resistir a posições preconcebidas como resposta única e que evitam, por discursos monológicos e algumas vezes até racionais, um posicionamento crítico e desmistifi-

$\overline{16}$ Cf. FONSECA, Ricardo Marcelo. O poder entre o direito e a norma: Foucault e Deleuze na teoria do Estado. In: Repensando a teoria do Estado. Belo Horizonte: Fórum, 2004, p. 263 e seguintes. 
cador de nossas heranças sociais.

Os discursos disciplinadores visam tornar o homem útil e dócil, atuando sobre uma massa confusa que consiga ser disciplinada para reproduzir um agrupamento ordenado, no qual o indivíduo é o alvo principal do poder. É

a ação sobre o corpo, o adestramento do gesto, a regulação do comportamento, a normalização do prazer, a interpretação do discurso, com o objetivo de separar, comparar, distribuir, avaliar, hierarquizar, tudo isso faz com que apareça pela primeira vez na história esta figura singular, individualizada - o homem - como produção do poder. ${ }^{17}$

Assim, diante desse abismo existente entre, de um lado, o "sujeito do direito" formal, teorizado pelo nosso legado iluminista (e pelos tradicionais códigos oitocentistas e novecentistas) e, de outro lado, o "sujeito real", de carne e osso, e que vivencia na prática relações jurídicas privadas e públicas no mundo material, que sofre inúmeras formas de controle e sujeição devido à "norma”, o jurista não pode ficar inerte. Deve, quem sabe, também buscar pensar o poder para além do Estado. ${ }^{18}$

Em resumo, a temática do poder em Foucault nos traz como lição a imperativa necessidade de escaparmos do discurso normalizador e nos levarmos a um momento de reflexão contínua dos atos sociais e de promoção de práticas discursivas de auto-responsabilização pela história que construímos.

\section{Conclusão}

A informação mais contextualizada do modernismo, na era da globalização, é dada por Milton Santos. Ele explica que a racionalização da sociedade foi ampliada a todos os recantos da vida social e hoje chega a novo patamar com a racionalização do próprio espaço geográfico.

O processo de racionalização cria novas relações entre espaço e tempo ${ }^{19}$, diante da emergência do meio técnico-científico-informacional, substituindo o meio natural, diagnosticado por Eduardo Bittar como uma substituição da razão pelo afeto, implantando a racionalidade como suporte de ações globalizadas.

Esta ordem global busca impor mecanismos de racionalidade única, que se guia por uma proposta organizacional, técnica, operacional. A proposta moderna, ampliada pela globalização, gerencia a manutenção da coerência normativa, segundo

\footnotetext{
17 MACHADO, Roberto. Op. cit., p. XX.

18 FONSECA, Ricardo Marcelo. Op. cit., p. 280.

19 Cf. SANTOS, Milton. Da totalidade ao lugar. São Paulo: Edusp, 2002, p. 165 e seguintes.
} 
uma escala desterritorializada do Estado de Direito, produtor dela própria para buscar sua racionalidade no território global.

Esse mecanismo de ampliação global torna-se um desafio a mais na realização dos direitos humanos fundamentais. Isso porque ele transfere à escala global, a luta pelo controle do poder social, tornando a chave ao enigma moderno globalizante, uma resposta a ser buscada também na esfera globalizante, como demonstra a proposta da democracia estendida. ${ }^{20}$

Porém, é preciso perceber que a Teoria do Direito, influenciada pelo pós-positivismo, procede uma substituição de paradigmas, buscando a valorização ética da atividade estatal, importando em uma ordem local orgânica que busque soluções na escala do cotidiano com incorporação, na leitura jurídica, de uma ética intimista de realização igualitária no próximo (alter).

O evolucionismo da escola francesa, tomada aqui como arquétipo de trabalho, representa na contemporaneidade a busca por esses ideais, como uma porta de entrada para a percepção destas realidades. E, ao mesmo tempo, uma porta de saída para a construção de um modelo que supere essas tensões das relações contraditórias de dominação.

Por último, alerte-se que o Martelo de Nietzsche serve tanto para destruir os paradigmas enclausuradores do homem, como para reconstruir o espaço de participação humana na formação de sua realidade, na recomposição da argumentação jurídica das relações sociais. Talvez a principal contribuição de Foucault seja a possibilidade metodológica de obrigar a leitura do direito e do poder como pressuposto, na realidade, de sua aplicação dentro do curso de uma longa história de repressão da realidade da existência humana.

20 Sobre a tese da Democracia Estendida vide o meu Estado, democracia e globalização. Rio de Janeiro: Forense, 2008. 


\section{Referências}

BAKUNIN, Mikhail. L’Illusion du Suffrage Universel. In: Ouvres, v. II. Paris: s/ed, 1907.

BITTAR, Eduardo C. B. Curso de filosofia política. São Paulo: Atlas, 2005.

. Razão e afeto, justiça e direitos humanos: dois paralelos cruzados para a mudança paradigmática.

Reflexões frankfurtianas e a revolução pelo afeto. Revista do Mestrado em Direito. Direitos Humanos Fundamentais. Edifieo, a. 8, n. 1, 2008, p. 99-128.

BOBBIO, Norberto. Estado, governo, sociedade. Para uma teoria geral da política. Rio de Janeiro: Paz e Terra, 1987.

FONSECA, Ricardo Marcelo. O poder entre o direito e a norma: Foucault e Deleuze na teoria do estado. In: Repensando a teoria do estado. Belo Horizonte: Fórum, 2004.

FOUCAULT, Michel. A ordem do discurso. São Paulo: Loyola, 2005.

A verdade e as formas jurídicas. Rio de Janeiro: NAU, 2003.

Microfísica do poder. Rio de Janeiro: Graal, 1979.

MACHADO, Roberto. Introdução. Por uma genealogia do poder. In: FOCAULT, Michel. Microfísica do poder. 8. ed. Rio de Janeiro: Graal, 1979.

NUNES, Benedito. Filosofia contemporânea. Belém: Edufpa, 2004.

PAINE, Thomas. Senso comune. Roma: Riuniti, 1978.

ROCHA, Luiz Alberto G. S. Estado, democracia e globalização. Rio de Janeiro: Forense, 2008.

ROCHA, Luiz Alberto G. S. Novo perfil do poder judiciário brasileiro (artigo submetido à avaliação de Conselho Editorial de periódico nacional).

SANTOS, Milton. Da totalidade ao lugar. São Paulo: Edusp, 2002.

TEBBIT, Mark. Philosophy of law: an introduction. Londres: Routledge, 2005. 